\title{
Air pollution exposure is associated with restrictive ventilatory patterns
}

\author{
To the Editor:
}

Exposure to ambient air pollution is associated with a substantial burden of morbidity and mortality worldwide [1]. In a recent paper, АDAM et al. [2] showed significantly impaired levels of forced expiratory volume in $1 \mathrm{~s}(\mathrm{FEV} 1)$ and forced vital capacity (FVC) associated with exposure to the ambient air pollutants nitrogen dioxide $\left(\mathrm{NO}_{2}\right)$ and particles with a 50\% cut-off aerodynamic diameter of $10 \mu \mathrm{m}$ (PM10) in 7613 adults included in the European Study of Cohorts for Air Pollution Effects (ESCAPE). Effect estimates for FVC were of similar magnitude (for $\mathrm{NO}_{2}$ ) or larger (for PM10) than those for FEV1. In line with these findings, ForBes et al. [3] showed negative associations of $\mathrm{PM}_{10}$ and $\mathrm{NO}_{2}$ with the level of FEV1 in 40329 adults included in the Health Survey for England between 1995 and 2001, whereas no significant associations with FEV1/FVC were observed. In 1997, the Swiss Study on Air Pollution and Lung Disease in Adults (SAPALDIA), including 9651 adults, showed negative associations of ambient air pollutants $\mathrm{NO}_{2}$ and $\mathrm{PM} 10$ with both FEV1 and FVC [4]. The effect estimates for FVC were stronger than for FEV1 for various pollutants, and this was consistently the case in most subgroups (according to smoking status and respiratory symptoms). Reduced FVC, with FEV1 being normal or reduced to a lesser degree than FVC, suggests restrictive rather than obstructive lung disease (in which FEV1 specifically is reduced, resulting in a low FEV1/FVC ratio). Thus, findings from several European studies suggest that restrictive rather than obstructive ventilatory patterns associate with long-term low levels of exposure to ambient air pollution. A study with slightly different findings is the German Study on the influence of Air Pollution on Lung Function, Inflammation and Ageing (SALIA), including 2593 women. This study also found negative associations of $\mathrm{NO}_{2}$ and $\mathrm{PM} 10$ exposure with both FEV1 and FVC, yet the effects estimates for FEV1 were stronger than for FVC, and consequently there were small significant negative associations with the FEV1/FVC ratio [5]. A review article concluded that despite biological plausible mechanisms, there is suggestive, but not conclusive evidence that chronic exposure to air pollution is associated with the prevalence and incidence of chronic obstructive pulmonary disease (COPD), a disease characterised by airway obstruction [6]. Thus far, no studies have focused explicitly on whether air pollution exposure is associated with obstructive or restrictive ventilatory patterns.

In the current study we looked explicitly at both obstructive and restrictive ventilatory patterns in relation to air pollution exposure, in the large Dutch population-based LifeLines Cohort Study (air pollution data for $>60000$ adults, mainly from the northern Netherlands) [7]. Within LifeLines, each residential address at the baseline visit (2007-2013) was geocoded and annual average exposure to $\mathrm{NO}_{2}, \mathrm{PM} 2.5, \mathrm{PM} 10$ and PM2.5 absorbance (PM2.5abs) was assigned to each address (X,Y coordinate) individually using land-use regression models developed within the ESCAPE study [2]. Associations of air pollutants with lung function levels at the baseline visit (pre-bronchodilator FEV1, FVC and FEV1/FVC) were assessed with linear regression models adjusted for sex, height, age, smoking status, pack-years, body mass index (BMI), environmental tobacco smoke exposure, highest level of obtained education, income and asthma. The asthma definition was based on a doctor diagnosis or a combination of symptoms and the use of asthma medication. Effect modification was tested by assessing interactions of air pollution levels with smoking (never/ever), sex, overweight (BMI $\geqslant 25 \mathrm{~kg} \cdot \mathrm{m}^{-2}$ ), asthma and airway obstruction (FEV1/FVC $<70 \%$ ).

Complete data were available for 51855 adults with a median (range) age of 44 (18-89) years, mean FEV1 $3546 \mathrm{~mL}$ (102\% predicted), FVC $4597 \mathrm{~mL}$ (112\% pred) and FEV1/FVC 77\%. Median (range) levels of exposure were $15.7\left(8.4-50.8 \mu \mathrm{g} \cdot \mathrm{m}^{-3} \mathrm{NO}_{2}, 15.4(14.8-20.2) \mu \mathrm{g} \cdot \mathrm{m}^{-3} \mathrm{PM} 2.5,24.0(23.7-31.7) \mu \mathrm{g} \cdot \mathrm{m}^{-3} \mathrm{PM} 10\right.$ and 0.95 (0.84-2.65) $10^{-5} \mathrm{~m}^{-1} \mathrm{PM} 2.5$ abs. Exposure levels were highly correlated (Spearman's r 0.49-0.93). Exposure to ambient air pollutants $\mathrm{NO}_{2}, \mathrm{PM} 10$ and PM2.5abs was associated with significantly lower FVC levels (table 1). Exposure to $\mathrm{NO}_{2}$ was associated with a lower level of $\mathrm{FEV} 1$, whereas no significant associations of the other air pollutants with FEV1 levels were observed. For all air pollutants the negative (nonsignificant) estimated effects on the level of FEV1 were smaller than on the level of FVC, which resulted in positive associations with their ratio (FEV1/FVC). PM2.5 exposure was not associated with any of the lung function variables investigated.

Associations between PM10 and PM2.5abs with FVC were generally stronger in females, subjects with BMI $\geqslant 25 \mathrm{~kg} \cdot \mathrm{m}^{-2}$, asthma and subjects with airway obstruction (table 1), yet without significant interactions. Associations between $\mathrm{NO}_{2}$ and FVC were similar in males and females, subjects without and with overweight, never- and ever-smokers, subjects without and with asthma, and without and with airway obstruction.

Importantly, in the current study we confirmed findings from previous European studies suggesting that long-term exposure to low levels of ambient air pollution is associated with restrictive ventilatory patterns [2-4]. Due to the cross-sectional design of the current study it was not possible to pinpoint whether observed 
TABLE 1 Associations between ambient air pollution exposure and lung function levels in the whole group and stratified by sex, overweight $\left(B M I<25 / \geqslant 25 \mathrm{~kg} \cdot \mathrm{m}^{-2}\right)$, smoking (never/ever), asthma (without/with) and airway obstruction (without/with $\mathrm{FEV} 1 / \mathrm{FVC}<70 \%$ )

\begin{tabular}{|c|c|c|c|c|c|c|c|c|c|c|c|}
\hline & All & Males & Females & $\mathrm{BMI}<25 \mathrm{~kg} \cdot \mathrm{m}^{-2}$ & $\mathrm{BMI} \geqslant 25 \mathrm{~kg} \cdot \mathrm{m}^{-2}$ & Never-smokers & Ever-smokers & Without asthma & With asthma & $\mathrm{FEV}_{1} / \mathrm{FVC} \geqslant \mathbf{7 0} \%$ & $\mathrm{FEV}_{1} / \mathrm{FVC}<70 \%$ \\
\hline Subjects & 51855 & 21608 (42) & $30247(58)$ & $24749(48)$ & 27106 (52) & 24617 (47) & 27238 (53) & 47424 (91) & 4431 (9) & 44956 (87) & $6899(13)$ \\
\hline \multicolumn{12}{|l|}{$\mathrm{FVC} \mathrm{mL}$} \\
\hline $\mathrm{NO}_{2}$ & $-57(-70--44)$ & $-61(-85--37)$ & $-56(-70--42)$ & $-41(-59--24)$ & $-58(-78--38)$ & $-53(-72--34)$ & $-59(-77--40)$ & $-57(-71--43)$ & $-56(-102--10)$ & $-50(-64--36)$ & $-70(-113--27)$ \\
\hline PM2.5 & $12(-55-79)$ & $71(-54-196)$ & $-34(-106-39)$ & $61(-28-150)$ & $5(-96-106)$ & $2(-93-97)$ & $36(-59-130)$ & $23(-47-93)$ & $-95(-337-147)$ & $19(-51-89)$ & $14(-207-235)$ \\
\hline $\mathrm{PM} 10$ & $-174(-248--101)$ & $-132(-268-4)$ & $-208(-287--128)$ & $-68(-163-27)$ & $-194(-308--80)$ & $-183(-286--79)$ & $-148(-252--44)$ & $-166(-242--89)$ & $-263(-524--2)$ & $-138(-214--62)$ & $-298(-550--47)$ \\
\hline PM2.5abs & $-92(-128--56)$ & $-78(-145--10)$ & $-106(-145--66)$ & $-51(-99--3)$ & $-89(-145--33)$ & $-90(-141--38)$ & $-86(-137--34)$ & $-86(-124--48)$ & $-155(-287--23)$ & $-77(-115--40)$ & $-118(-241-4)$ \\
\hline \multicolumn{12}{|c|}{ 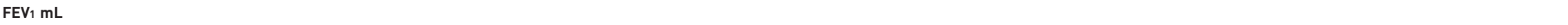 } \\
\hline $\mathrm{NO}_{2}$ & $-18(-30--7)$ & $-33(-53--12)$ & $-11(-22-1)$ & $-12(-27-3)$ & $-20(-36--3)$ & $-17(-33--1)$ & $-20(-36--4)$ & $-19(-31--8)$ & $-7(-51-36)$ & $-21(-32--10)$ & $-44(-77--11) *$ \\
\hline $\mathrm{PM}_{2.5}$ & $27(-30-83)$ & $57(-50-164)$ & $5(-55-66)$ & $47(-29-122)$ & $20(-66-105)$ & $-12(-91-66)$ & $72(-10-154)$ & $28(-30-86)$ & $45(-181-272)$ & $25(-31-80)$ & $21(-149-192)$ \\
\hline $\mathrm{PM}_{10}$ & $-21(-83-42)$ & $-1(-118-116)$ & $-37(-103-29)$ & $25(-55-106)$ & $-35(-131-61)$ & $-47(-133-38)$ & $9(-80-99)$ & $-19(-83-45)$ & $-21(-266-223)$ & $-27(-87-33)$ & $-191(-385-4)$ \\
\hline PM2.5abs & $-14(-45-17)$ & $-8(-67-50)$ & $-20(-53-13)$ & $3(-38-44)$ & $-14(-61-33)$ & $-24(-67-19)$ & $-2(-47-43)$ & $-12(-44-20)$ & $-25(-149-98)$ & $-20(-50-10)$ & $-65(-160-30)$ \\
\hline \multicolumn{12}{|l|}{$\mathrm{FEV}_{1} / \mathrm{FVC} \%$} \\
\hline $\mathrm{NO}_{2}$ & $0.5(0.4-0.7)$ & $0.2(0.0-0.5)$ & $0.7(0.6-0.9)^{*}$ & $0.4(0.2-0.6)$ & $0.5(0.3-0.8)$ & $0.5(0.3-0.7)$ & $0.5(0.3-0.7)$ & $0.5(0.4-0.7)$ & $0.7(0.0-1.4)$ & & \\
\hline $\mathrm{PM} 2.5$ & $0.3(-0.5-1.1)$ & $-0.1(-1.4-1.2)$ & $0.6(-0.4-1.5)$ & $-0.1(-1.2-0.9)$ & $0.3(-0.8-1.5)$ & $-0.3(-1.4-0.7)$ & $0.9(-0.2-2.0)$ & $0.1(-0.7-0.8)$ & $3.5(0.0-7.1)^{*}$ & & \\
\hline $\mathrm{PM}_{10}$ & $2.2(1.4-3.1)$ & $1.5(0.1-2.9)$ & $2.7(1.7-3.7)$ & $1.3(0.2-2.5)$ & $2.4(1.1-3.6)$ & $1.9(0.8-3.0)$ & $2.3(1.0-3.5)$ & $2.1(1.2-2.9)$ & $3.9(0.1-7.6)$ & & \\
\hline PM2.5abs & $1.1(0.7-1.6)$ & $0.8(0.1-1.5)$ & $1.4(0.8-1.9)$ & $0.7(0.2-1.3)$ & $1.2(0.5-1.8)$ & $0.9(0.4-1.5)$ & $1.2(0.6-1.9)$ & $1.1(0.6-1.5)$ & $2.1(0.2-4.0)$ & & \\
\hline
\end{tabular}

Data are presented as $\mathrm{n}, \mathrm{n}(\%)$ or $\mathrm{B}(95 \% \mathrm{CI})$. BMI: body mass index; FEV1: forced expiratory volume in $1 \mathrm{~s}$; FVC: forced vital capacity. Linear regression models were adjusted for sex, height, age, smoking status (ex- and current smoking), pack-years smoked, BMI (continuous), environmental tobacco smoke exposure, highest level of obtained education, income and asthma. Effect estimates are presented per $10 \mu \mathrm{g} \cdot \mathrm{m}^{-3}$ for nitrogen dioxide $\left(\mathrm{NO}_{2}\right)$ and particles with a $50 \%$ cut-off aerodynamic diameter of $10 \mu \mathrm{m}(\mathrm{PM} 10)$, per $5 \mu \mathrm{g} \cdot \mathrm{m}^{-3}$ for particles with a $50 \%$ cut-off aerodynamic diameter of $2.5 \mu \mathrm{m}$ (PM2.5) and per $10^{-5} \cdot \mathrm{m}^{-1}$ for PM2.5 absorbance (PM2.5abs). Effect estimates in bold indicate significant associations (p<0.05). Exposure levels are highly correlated: Spearman's $r$ for $\mathrm{NO}_{2}$ with PM2.5, PM10 and PM2.5abs are 0.49, 0.73 and 0.79, respectively; Spearman's $r$ for PM2.5 with PM10 and PM2.5abs are 0.69 and 0.64 respectively; and for PM10 with PM2.5abs Spearman's $r$ is $0.93 .{ }^{*}: p<0.05$. 
associations are due to reduced lung growth, accelerated decline in lung function, or both. In the ESCAPE study, significant associations between ambient air pollutants and FVC and FEV1 levels were observed, yet there were no associations with annual lung function decline [2]. These observations suggest that associations between air pollution exposure and lung function levels in adulthood are rather reflecting reduced lung growth than accelerated lung function decline. This is in line with observations in children showing reduced age-related increase in FVC associated with air pollution exposure $[8,9]$. Moreover, in childhood, estimated effects of exposure to various air pollutants were already found to be larger for FVC than for FEV1 [10, 11]. Additionally, decreases in air pollution levels have been associated with increased growth of FEV1 and FVC in children, with largest effects on FVC [12], and with improvements in FVC, but not in FEV1, in adults [13].

The current study suggests that associations of PM10 and PM2.5abs with impaired lung function levels in adults are stronger in females, subjects with higher BMI and with underlying respiratory diseases such as asthma or COPD, whereas such differential effects were not observed for $\mathrm{NO}_{2}$ exposure. The ESCAPE study found stronger effects of $\mathrm{NO}_{2}$ exposure on FEV1 and FVC in females, subjects with asthma and in obese subjects, with the latter showing significant interaction with $\mathrm{NO}_{2}$ [2]. In general, and in line with our observations, most studies thus far have not observed clear differences in effect estimates between smokers and nonsmokers $[2,3,5]$. Identifying susceptible subgroups in the population may be important from a public health perspective, e.g. exposure limits may be determined based on the most susceptible subgroups. Moreover, identifying such (genetically) susceptible subgroups may pinpoint potential (biological) mechanisms underlying observed associations [14], which will give rise to further studies in experimental settings.

Restrictive ventilatory patterns with exposure to ambient air pollution may reflect pulmonary fibrosis, a disease which has thus far largely been understudied in relation to air pollution exposure in large-scale epidemiological studies [15]. Yet, further studies are warranted that include additional measurements, such as total lung capacity, in subsets of individuals with low FVC, to confirm true restrictive ventilatory effects of air pollution exposure.

To conclude, low levels of ambient air pollution are associated with restrictive ventilatory patterns. Both epidemiological and experimental studies are warranted to confirm true restrictive ventilatory effects of air pollution exposure and to elucidate underlying biological mechanisms leading to a disease that is largely understudied in relation to air pollution exposure, i.e. pulmonary fibrosis. Identifying susceptible subgroups and underlying biological pathways may contribute to lowering the substantial burden of respiratory disease related to ambient air pollution exposure.

$\boldsymbol{0}$ @ERSpublications

Exposure to ambient air pollution is associated with restrictive ventilatory patterns http://ow.ly/QWbD30236J1

Kim de Jong ${ }^{1,2}$, Judith M. Vonk ${ }^{1,2}$, Wilma L. Zijlema ${ }^{1}$, Ronald P. Stolk ${ }^{1}$, Diana A. van der Plaat ${ }^{1,2}$, Gerard Hoek ${ }^{3}$, Bert Brunekreef ${ }^{3,4}$, Dirkje S. Postma ${ }^{2,5}$ and H. Marike Boezen ${ }^{1,2}$ on behalf of the LifeLines Cohort Study Group ${ }^{6}$ ${ }^{1}$ Dept of Epidemiology, University of Groningen, University Medical Center Groningen, Groningen, The Netherlands. ${ }^{2}$ Groningen Research Institute for Asthma and COPD (GRIAC), University of Groningen, University Medical Center Groningen, Groningen, The Netherlands. ${ }^{3}$ Division of Environmental Epidemiology, University of Utrecht, Institute for Risk Assessment Sciences (IRAS), Utrecht, The Netherlands. ${ }^{4}$ Julius Center for Health Sciences and Primary Care, University Medical Center Utrecht, Utrecht, The Netherlands. ${ }^{5}$ Dept of Pulmonary Diseases, University of Groningen, University Medical Center Groningen, Groningen, The Netherlands. ${ }^{6}$ A list of members of the LifeLines Cohort Study Group can be found in the acknowledgements section.

Correspondence: H. Marike Boezen, University of Groningen, University Medical Center Groningen, Department of Epidemiology, Hanzeplein 1, 9700 RB Groningen, The Netherlands. E-mail: h.m.boezen@umcg.nl

Received: March 172016 | Accepted after revision: June 142016 | First published online: Aug 042016

Support statement: K. de Jong was supported by the Groningen University Institute for Drug Exploration (GUIDE) and grant number 4.113 .007 of the Lung Foundation Netherlands. D.A. van der Plaat was supported by grant number 4.113.007 of the Lung Foundation Netherlands. The LifeLines Cohort Study was supported by the Dutch Ministry of Health, Welfare and Sport, the Ministry of Economic Affairs, Agriculture and Innovation, the province of Groningen, the European Union (regional development fund), the Northern Netherlands Provinces (SNN), the Netherlands Organisation for Scientific Research (NWO), University Medical Center Groningen (UMCG), University of Groningen, de Nierstichting (the Dutch Kidney Foundation) and the Diabetes Fonds (the Diabetic Foundation). Funding information for this article has been deposited with the Open Funder Registry.

Conflict of interest: Disclosures can be found alongside this article at erj.ersjournals.com

Acknowledgements: The members of the LifeLines Cohort Study are as follows. B.Z. Alizadeh (Department of Epidemiology), R.A. de Boer (Department of Cardiology), H.M. Boezen (Department of Epidemiology), M. Bruinenberg, L. Franke (Department of Genetics), P. van der Harst (Department of Cardiology), H.L. Hillege (Departments of Epidemiology and Cardiology), M.M. van der Klauw (Department of Endocrinology), G. Navis (Department of Internal 
Medicine, Division of Nephrology), J. Ormel (Department of Psychiatry, Interdisciplinary Center of Psychopathology of Emotion Regulation (ICPE)), D.S. Postma (Department of Pulmonology), J.G.M. Rosmalen (Department of Psychiatry, ICPE), J.P. Slaets (University Center for Geriatric Medicine), H. Snieder (Department of Epidemiology), R.P. Stolk (Department of Epidemiology), B.H.R. Wolffenbuttel (Department of Endocrinology) and C. Wijmenga (Department of Genetics), all at University of Groningen, University Medical Center Groningen, Groningen, The Netherlands.

\section{References}

1 World Health Organization. Burden of Disease from Ambient Air Pollution for 2012. www.who.int/phe/health_topics/ outdoorair/databases/AAP_BoD_results_March2014.pdf?ua=1 Date last accessed: November 12, 2015. Date last updated: March, 2014.

2 Adam M, Schikowski T, Carsin AE, et al. Adult lung function and long-term air pollution exposure. ESCAPE: a multicentre cohort study and meta-analysis. Eur Respir J 2015; 45: 38-50.

3 Forbes LJ, Kapetanakis V, Rudnicka AR, et al. Chronic exposure to outdoor air pollution and lung function in adults. Thorax 2009; 64: 657-663.

4 Ackermann-Liebrich U, Leuenberger P, Schwartz J, et al. Lung function and long term exposure to air pollutants in Switzerland. Study on Air Pollution and Lung Diseases in Adults (SAPALDIA) Team. Am J Respir Crit Care Med 1997; 155: 122-129.

5 Schikowski T, Sugiri D, Ranft U, et al. Long-term air pollution exposure and living close to busy roads are associated with COPD in women. Respir Res 2005; 6: 152.

6 Schikowski T, Mills IC, Anderson HR, et al. Ambient air pollution: a cause of COPD? Eur Respir J 2014; 43: 250-263.

7 Scholtens S, Smidt N, Swertz MA, et al. Cohort Profile: LifeLines, a three-generation cohort study and biobank. Int J Epidemiol 2015; 44: 1172-1180.

8 Gauderman WJ, Avol E, Gilliland F, et al. The effect of air pollution on lung development from 10 to 18 years of age. N Engl J Med 2004; 351: 1057-1067.

9 Berend N. Contribution of air pollution to COPD and small airway dysfunction. Respirology 2016; 21: 237-244.

10 Gehring U, Gruzieva O, Agius RM, et al. Air pollution exposure and lung function in children: the ESCAPE project. Environ Health Perspect 2013; 121: 1357-1364.

11 Peters JM, Avol E, Gauderman WJ, et al. A study of twelve Southern California communities with differing levels and types of air pollution. II. Effects on pulmonary function. Am J Respir Crit Care Med 1999; 159: 768-775.

12 Gauderman WJ, Urman R, Avol E, et al. Association of improved air quality with lung development in children. N Engl J Med 2015; 372: 905-913.

13 Boogaard H, Fischer PH, Janssen NA, et al. Respiratory effects of a reduction in outdoor air pollution concentrations. Epidemiology 2013; 24: 753-761.

14 Boezen HM, Vonk JM, van der Zee SC, et al. Susceptibility to air pollution in elderly males and females. Eur Respir J 2005; 25: 1018-1024.

15 Johannson KA, Balmes JR, Collard HR. Air pollution exposure: a novel environmental risk factor for interstitial lung disease? Chest 2015; 147: 1161-1167.

\section{Near infrared spectroscopy for the assessment of peripheral tissue oxygenation in pulmonary arterial hypertension}

\section{To the Editor:}

Pulmonary arterial hypertension $(\mathrm{PAH})$ is characterised by increased pulmonary vascular resistance and results in increased morbidity and mortality due to right heart failure and a progressive decline in cardiac output $[1,2]$. The latter disturbs oxygen delivery to the periphery and may lead to pathological changes in tissue oxygenation. The balance between global oxygen supply and demand is reflected in mixed venous oxygen saturation $\left(\mathrm{S}_{\mathrm{VO}_{2}}\right)$, an index that is generally reduced in patients with $\mathrm{PAH}$ [3]. $\mathrm{S}_{\mathrm{VO}}$ at baseline is one of the strongest predictors of survival in $\mathrm{PAH}[4-6]$; this is also true for changes in $\mathrm{SvO}_{2}$ during follow-up [5]. Cut-off values of $60 \%$ [7] and 65\% [5] have been used to distinguish between prognostic groups suggesting that these may be suitable treatment goals. $\mathrm{SvO}_{2}$ is measured invasively in the pulmonary artery, where venous blood mixes after circulating through the superior and inferior vena cava, coronary sinuses and the right-heart chambers.

Spatially resolved near infrared spectroscopy (NIRS) offers a noninvasive, rapidly responsive method for measuring skeletal muscle oxygenation by examining absorption differences in the near-infrared spectrum of 